\title{
Developing a Framework to Measure Competency Levels of Students with Special Needs to Attend Advanced /Vocational Courses
}

\author{
Hishamuddin Ahmad ${ }^{1}$, SitiEshah Mokshein ${ }^{2}$, MohdRazimi Husin ${ }^{3}$, Norfishah Mat Rabi ${ }^{4}$, Abdul \\ Rahim Hamdan $^{5}$ \& Ismail Yusuf Panessai ${ }^{6}$
}

\author{
${ }^{1,2,3,5}$ Department of Educational Studies, Faculty of Human Development, UniversitiPendidikan Sultan Idris \\ ${ }^{4}$ Department of Special Education, Faculty of Human Development, UniversitiPendidikan Sultan Idris \\ ${ }^{6}$ Department of Computerization, Faculty of Art, Computing and Creative Industry, UniversitiPendidikan Sultan \\ Idris \\ hishamuddin.a@fpm.upsi.edu.my ${ }^{1}$
}

Article History:Received:11 January 2021; Accepted: 27 February 2021; Published online: 5 April 2021

\begin{abstract}
Students with special needs (MBK) should not be considered students who fail or have no future. Although MBKs are those with intellectual problems or shortcomings, they may have strengths or powers in other areas that need to be identified and improved. The respondents who were the sample of this study were 44 people consisting of MBK with intellectual disability, dyslexia, and visual impairment. This research employed instruments of academic success perception $(\alpha=0.78$, construct validity $=0.85)$, multiple intelligences $(\alpha=0.86$, construct validity $=0.87$ ), and interview protocol to recognise the dominant aspects of MBK to build further the framework of courses advanced/vocational following the interests of the respondents. The dominant aspect for the perception of academic success was External / Future $(\mu=3.43, \mathrm{SD}=0.38)$, while the most dominant aspect for multiple intelligences was Visual-Spatial Intelligence $(\mu=3.22, \mathrm{SD}=0.46)$. The dominant aspects were also very relevant to MBK's choice of advanced/vocational courses, particularly cooking, bakery, sewing, carpentry, entrepreneurs, logistics, and mechanics. It is hoped that this study's conclusions can present information on the courses that are the authentic choice among MBKs for consideration by stakeholders in offering advanced/vocational courses to this group.
\end{abstract}

Keywords: Framework, Competency, Vocational, Special Needs.

\section{INTRODUCTION}

Among the Special Education Policy contents is to assure that the education program for disabled students is fitting and proper to their respective abilities to be independent and continue a quality life (Special Education Division, 2014). According to the Ministry of Education Malaysia (2020a), 'Special Needs Students' (MBK), means students certified by medical practitioners, or opticians, audiologists or psychologists as the case may be, whether in government or private service as students who have a visual impairment, hearing impairment, speech impairment, physical disability, mental disability, learning disabilities or any combination of these disabilities. The Ministry of Education Malaysia (2020b) categorised learning problems into Attention Deficit Hyperactivity Disorder (ADHD), Autism, Intellectual Disability, slow learner, Down Syndrome, Dyslexia, and others.

To beat the problem of MBK drop out due to the asserted conditions, the Ministry of Education Malaysia (MOE) formed the MOE Special Education Program(Ministry of Education Malaysia, 2020c). The educational programs submitted were Special Rehabilitation Program, Inclusive Education Program, Integrated Special Education Program (PPKI), and Special Education Service Center (3PK). Apart from that, MOE also executed the initiative by providing 'MBK Career Transition Program' which refers to activities supporting MBK to go through the transition process in secondary schools before entering the career world. The program, which requires the cooperation of the MBK family, includes six components starting from Form One to Form Five and was designed to enhance MBKs' competencies, especially in preparation for a career that is fit for them later.

Nevertheless, studies on courses that meet the requirements of MBK are less conducted. It may be based on the assumption that MBK is not smart enough to express the course they want when they have the opportunity to pursue post-secondary school education. They can engage in adding to the progress of the country. Students with learning disabilities should not be regarded as students who fail or have no future. Even though MBKs are those with intellectual difficulties or weaknesses, they may have strengths or preferences in other fields that need to be known and developed.

Through MOE letter with reference to KPM.600-14/1/60/JLD.7 (76) dated 29 January 2018 entitled Implementation of Psychometric Assessment for Primary and Secondary Schools in 2018, the Multiple Intelligences Inventory (IKeP) was administered at the primary school level (in Standard 6) and high school (in Form 3). Nonetheless, IKeP, which measures MOE's nine constructs for students in Form 3 (MOE Examination Board, 2014), was quite intricate to implement to MBK. Apart from being divided into two papers, precisely efficiency and perception, the number of items was extensive and time-consuming. MBK is a group that quickly 
loses focus when presented with complex instruments and the one that takes a long time to complete. It is based on the findings of Vasuden (2017) study, which affirmed that MBK needs more time to gain skills than their typical counterparts. Therefore, a more straightforward instrument without dismissing the quality aspect should be applied to MBK.

Among the Special Education Policy contents is to secure that the education program for MBK is apposite and applicable to their respective abilities to be self-sufficient and experience a quality life (Special Education Division, 2014). However, the 'multiple intelligence' aspect of MBK is not determined by instruments that are more appropriate to their situation. As a result of the dominant aspect in various bits of intelligence that are not explored from among the MBK, they are often offered with learning in skills or vocational areas according to the course's availability. Although students' skills can be developed through the courses given, it is more beneficial if the field offered is dominant in them. Therefore, this study was attended to develop a framework to measure students' level of competence with special needs to follow advanced/vocational courses. It was accomplished by identifying the weaknesses and strengths of MBK in terms of 'perception of academic success' and 'diverse intelligence' and suggesting further courses that MBK intends themselves. It is quintessential so that the school and stakeholders can provide the optimal space and opportunity to grow their potential.

\section{RESEARCH METHOD}

This study was quantitative with survey design and supported by qualitative data by interview. According to the Perak State Education Department (2018), there are 76 National Secondary Schools (SMK) that offer Special Education Integration Program (PPKI). Nevertheless, seven schools offer PPKI in Batang Padang District, Perak (Perak State Education Department, 2018). The National Secondary Schools (SMK) are under the Batang Padang District Education Office (PPD), Perak.

\subsection{Sampling}

The number of students who hold learning difficulties and follow PPKI is not many in a school. According to Kail (2001), almost four per cent of the world's population consists of special individuals or children with special needs or MBK. Class sizes for Special Education Schools (SPK) or PPKI are one to seven people, and the school can start another class if deemed necessary (Special Education Division, 2014). At the same time, the Special Education Division (2014) asserted that the presence of only one MBK qualifies the school to initiate special education classes. MBK who follow PPKI is placed in a class consisting of students of different ages and various levels. At the secondary school level, a typical 13-year-old student will usually be placed in Form 1 and then levels up to Form 5 in line with their increasing age. For students in the MBK category, their age does not reflect the level at which they are because it will depend on their academic level, which is customarily relatively low compared to typical students.

Hence, students who agreed to be respondents were randomly selected from schools that were sampled without based on their form levels. The number of students elected from each school which was also a sample of this study was 44. As an additional note, due to the COVID-19 pandemic that hit the globe, including Malaysia, two schools initially selected as a sample withdrew from this study. It led this study to be attended only in five schools compared to seven schools as intended.

The respondents were MBKs in the category of Intellectual disability with intelligencesignificantly below average. They had difficulties in comprehension and life function, dyslexia with imperfect ability to read and write, and visual impairment who had an impairment in vision even with correction. Visual impairment conditions unfavourably influence a student's educational performance. It creates barriers in reading and leads to a range of eyes conditions.

\subsection{Research Instrument}

The instrument of this study was divided into three parts, namely A (Demographic Information), B (Perception of Academic Success), and C (Multiple Intelligences). Cohen and Swerdlik (2002) proposed that instrument construction involves three phases: planning, developing, and testing and validating. In the education study, Lay and Khoo (2014) also submitted that the questionnaire comprises KISS principles (Keep-It-Short-Simple). This study's research instrument did not follow these phases because it was adapted from preceding studies. Nevertheless, the adapted items were reviewed by instrument experts to ensure that the use of language adjustments that are easy to understand by the MBK group, concise, and clear so that respondents could complete it in a short period. The instruments employed were also piloted to test their reliability, validity, and suitability. A pilot study was conducted at another school around Batang Padang District, Perak to recognise problems from instruments adapted to modifications. Improvements and modifications to the instruments, including the interview protocol, were completed based on the pilot study analysis results before the instrument was administered to the respondents in the actual study. 


\subsubsection{Part A - Demographic}

This section's items are related to demographic information that comprises information on the respondents' school Name, Gender, Age, and main ambitions.

\subsubsection{Part B - Academic Success Perception}

The instrument to measure the perception of academic success used in this study was adapted, which did not involve the planning and developing phases. Nevertheless, expert confirmation of the items was obtained to suit the 'climate' in Malaysia. This instrument was adapted from a modification of the Academic Success Inventory for College Students (ASICS) instrument originally formulated by Prevatt et al., (2011). This instrument initially contained 50 items with ten factors namely: Career Determination, Internal Motivation / Confidence, Future External Motivation, General Academic Skills, Lack of Anxiety, Focus, Current External Motivation, Personal Adjustment, Perceptions of Teacher Effectiveness, and Socialisation. However, according to experts who reviewed this instrument, two items need to be removed as they were not closely related to the respondents among MBKs. The first item related to 'drink' that refers to drinking alcoholic beverages was removed because it was found unfit for students' culture and the environment in Malaysia who are mostly Muslims and are not allowed to drink alcoholic beverages. The second item was related to 'scholarship' from the government, which is usually only suitable for brilliant typical students. Thus, the real number of items remaining was 48 items (Table 1).

In this study, the response scale was based on 5 points from ' 1 ' (strongly disagree) to ' 5 ' (strongly agree) or, in more detail, Strongly Disagree, Disagree, Not Sure, and Strongly Agree. The scale aided researchers in data collection and analysis more easily because respondents had fewer response options and more comfortable making decisions.

Table 1. Academic Success Perception Item Distribution

\begin{tabular}{|c|c|c|c|}
\hline No. & Construct & $\begin{array}{l}\text { No. of } \\
\text { Items }\end{array}$ & Item \\
\hline 1 & Career Determination & 4 & Item45, Item46, Item47, Item48 \\
\hline & Internal Motivation / & & \\
\hline 2 & Confidence & 8 & Item6, Item9, Item10, Item11, Item18, Item20, Item28, Item29 \\
\hline 3 & $\begin{array}{l}\text { Future } \\
\text { Motivation }\end{array}$ & 4 & Item7, Item19, Item37, Item40 \\
\hline 4 & General Academic Skills & 12 & $\begin{array}{l}\text { Item4, Item8, Item } 12 \text {, Item } 14 \text {, Item23, Item30, Item32, Item33, } \\
\text { Item41, Item42, Item43, Item } 44\end{array}$ \\
\hline 5 & Lack of Anxiety & 3 & Item3, Item 15, Item 31 \\
\hline 6 & Focus & 4 & Item2, Item5, Item 16, Item 21 \\
\hline 7 & $\begin{array}{l}\text { Current } \quad \text { Motivation } \\
\text { Motivation }\end{array}$ & 2 & Item 26, Item 38 \\
\hline 8 & Personal Adjustments & 3 & Item1, Item25, Item39 \\
\hline 9 & $\begin{array}{l}\text { Perception of Teacher } \\
\text { Effectiveness }\end{array}$ & 5 & Item22, Item24, Item27, Item34, Item35 \\
\hline 10 & $\begin{array}{l}\text { Socialisation } \\
\text { Total }\end{array}$ & $\begin{array}{l}3 \\
48\end{array}$ & Item 13, Item 17, Item 36 \\
\hline
\end{tabular}

\subsubsection{Part C - Multiple Intelligence}

This section's items are also adapted based on the Theory of Multiple Intelligences (Gardner, 1983; Gardner, 2011). This instrument contains nine constructs and consists of 63 items in total (Table 2). Item response used a 5-point response scale from ' 1 ' (strongly disagree) to '5' (strongly agree) or in more detail, Strongly Disagree, Disagree, Not Sure, Agree, and Strongly Agree. Instrument experts evaluated the items used to ensure their suitability in respondents' context among MBKs and Malaysia. Slight improvements were made to items specifically related to the language that is easy to follow, brief, and transparent so that respondents could finish it in a short time.

Table 2. Multiple Intelligence Item Distribution

\begin{tabular}{llll}
\hline No & Intelligence Construct & No. of Items & Item \\
\hline 1 & Linguistics & 7 & Li1 - Li7 \\
\hline
\end{tabular}


Developing a Framework to Measure Competency Levels of Students with Special Needs to Attend Advanced /Vocational Courses

\begin{tabular}{llll}
\hline 2 & Logic-Mathematics & 7 & LM1 - LM7 \\
3 & Visual-Spatial (Space) & 7 & VS1 - VS7 \\
4 & Kinesthetic-Body & 7 & KB1 - KB7 \\
5 & Music & 7 & Mu1 - Mu7 \\
6 & Interpersonal & 7 & IE1 - IE7 \\
7 & Intrapersonal & 7 & IA1 - IA7 \\
8 & Naturalist & 7 & Na1 - Na7 \\
9 & Existential & 7 & Ex1 - Ex7 \\
& Total & 63 & \\
\hline
\end{tabular}

\subsubsection{Part D - Interview Protocol}

The interview protocol section was formulated to obtain more in-depth information from the respondents' opinions on the field of learning / advanced/vocational courses suitable for themselves in the future. This information could support and further strengthen the quantitative data that was obtained.

\subsection{Research Procedure}

After obtaining permission from the Educational Planning and Research Division (EPRD), MOE, District Education Office (PPD), Batang Padang, and the schools involved, the researchers collected data from students in the MBK category that were randomly selected or voluntarily participated in this study. The researchers administered the questionnaire face to face with all respondents with the help of school officials or teachers' involvement and structured interviews with all the respondents. The questionnaire data collected were analysed. In addition to quantitative data analysed with statistical software, structured interview data were also analysed qualitatively.

\section{RESULTS AND ANALYSIS}

\subsection{Demographic}

As in Table 3, demographically, most MBK respondents were male (63.6\%), while the female was 36.4 percent. Certain assumptions abroad stated that female MBK will usually only be placed at home and will usually not be seen in the education system than male MBK. In fact, in underdeveloped nations, the birth of female MBK is sometimes not even registered. Nevertheless, this is unlikely not happen in Malaysia because it makes primary education compulsory when a citizen child reaches six. The Education Act 1996 through Section 29A (2) requires parents to send their children to primary school for six years, and if they fail, the parents can be fined or jailed or both. Nevertheless, the act is proposed to be revised, so that compulsory education covers up to Form 5 for all Malaysians.

The majority of respondents (12 people) were 16 years old, and only one was 13 years old. Other respondents aged 19years old (4), 18 years old (11), 17 years old (9), 15 years old (4), and 14 years old (3). The majority of respondents were from SMK Bidor (25\%) and SMK Khir Johari (22.7\%). It noted that MBK parents in these schools realised the value of sending their children to schools with PPKI to improve their skills and future demands.

Table 3. Respondents' Profile

\begin{tabular}{llll}
\hline Profile & Characteristics & Frequency & Percentage (\%) \\
\hline Gender & Male & 28 & 63.6 \\
& Female & 16 & 36.4 \\
\hline Age (Years Old) & 13 & 1 & 2.3 \\
& 14 & 3 & 6.8 \\
& 15 & 4 & 9.1 \\
& 16 & 12 & 27.3 \\
& 17 & 9 & 20.5 \\
& 18 & 11 & 25.0 \\
& 19 & 4 & 9.1 \\
\hline School & SMK Bid & 11 & 25.0 \\
& SMK KJo & 10 & 22.7 \\
& SMK Sli & 8 & 18.2 \\
& SMK B2020 & 9 & 20.5 \\
Total & SMK SKr & 6 & 13.6 \\
\hline
\end{tabular}


All respondents in this study were from the Special Education Integration Program (PPKI). MBK from PPKI has the opportunity to sit for the 'Form 3 Assessment' (PT3) while in Form 3. If their results are promising and meet the minimum requirements, MBK can continue their studies to Form 4 and 5 in National Secondary Schools (Vocational) or continue PPKI.

\subsection{Perception of academic success among MBK}

From item analysis with statistical software, the academic success perception instrument's reliability value was 0.78 , with a construct validity value of 0.85 . It showed that this instrument was good in internal consistency and validity and could provide an acceptable output. In an attempt to interpret the descriptive score, the mean score was categorised into three levels, particularly low, average, and high. The interpretation of the mean score used for the descriptive data analysis results is as in Table 4.

Table 4. Score Interpretation

\begin{tabular}{ll}
\hline Mean Score & Interpretion \\
\hline 1.00 hingga 2.00 & Low \\
2.01 hingga 3.00 & Average \\
3.01 hingga 4.00 & High \\
\hline
\end{tabular}

The outcomes of the study (Figure 1) found that the highest mean score was for the External / Future Motivation construct $(\mu=3.43, \mathrm{SD}=0.38)$, followed by External / Current Motivation $(\mu=3.35, \mathrm{SD}=0.53)$. Nevertheless, the Socialisation construct was the lowest with $(\mu=2.4, \mathrm{SD}=0.61)$. It proved that respondents were aware thatexternal motivation is a priority for them to succeed academically. At the same time, respondents were also aware that socialisation is the element that least contributes to academic success. Although MBKs have a perception that socialisationis a factor that reduces academic achievement, they should also be encouraged to communicate socially with friends and mainstream students at the same school. Social interaction is also essential to grow MBK's self-confidence in the mainstream school environment to succeed in the chosen field. According to the University of Massachusetts (2021), one ingredient of inclusive success is the extent to which MBKs could feel that they are part of the mainstream partner. Thus, helping MBK develop positive social interactions with their peers is very beneficial.

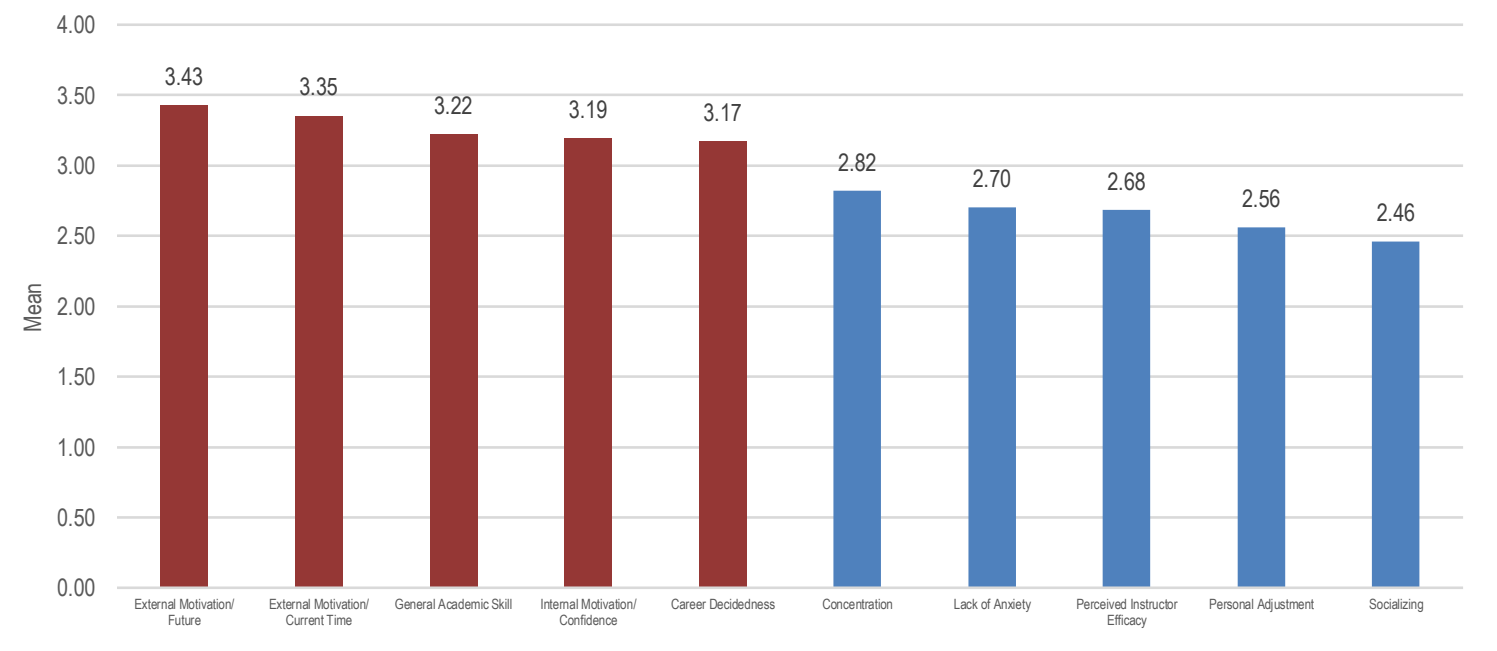

Figure 1. Respondents' academic success perception

Findings from the analysis with ANOVA also observed no significant difference $(\mathrm{F}(2,41)=0.942, \mathrm{p}=0.398)$ between ASICS scores among MBKs with intellectual disability, dyslexia, and vision impairments. Hishamuddin et al. (2019) in their study discovered that the 'Perceived Instructor Efficacy' and 'Personal Adjustment'constructs were two of the main factors that preferred by the highest ability students group. Nevertheless, in this study, 'External Motivation (Future)' and 'External Motivation (Current Time)' are two main factors for the disability students' perception in their academic success. It indicated that students categorised as 'special need' are more likely to choose external motivation as a vital factor if they want to thrive in their academics. They need motivation in all ways. Nevertheless, this study's outcomes were not in line with the study's results by Prevatt et al. (2011) where General Academic Skills constructs showed the highest internal consistency, while the External / Current Motivation construct exhibited the lowest internal consistency. It was because Prevatt et al. did not use disability students as their respondents. 
According to Daniel and Cooc (2018), students who report high intrinsic motivation levels perform better on academic tasks than students who report low intrinsic motivation levels. In this research, whereby the respondents were among students with a disability, a high internal motivation score did not mean that they were excellent academically. However, the high score might symbolise the students' internal motivation to perform better on academic tasks than other disability students who were not in the school environment. It also reflected that students with a disability could cope with continuing their learning in the mainstream school environment.

\subsection{Multiple intelligences are dominant among MBK}

From item analysis with statistical software, the reliability value of various intelligence instruments was 0.86 , with construct validity value 0.87 . It revealed that this instrument was also useful in terms of internal consistency and validity and could provide an acceptable output. The findings of this study (Figure 2) determined that the highest mean score was Visual-Spatial Intelligence $(\mu=3.22, \mathrm{SD}=0.46)$, while the lowest was Kinesthetic $(\mu=$ $2.89, \mathrm{SD}=0.42$ ).

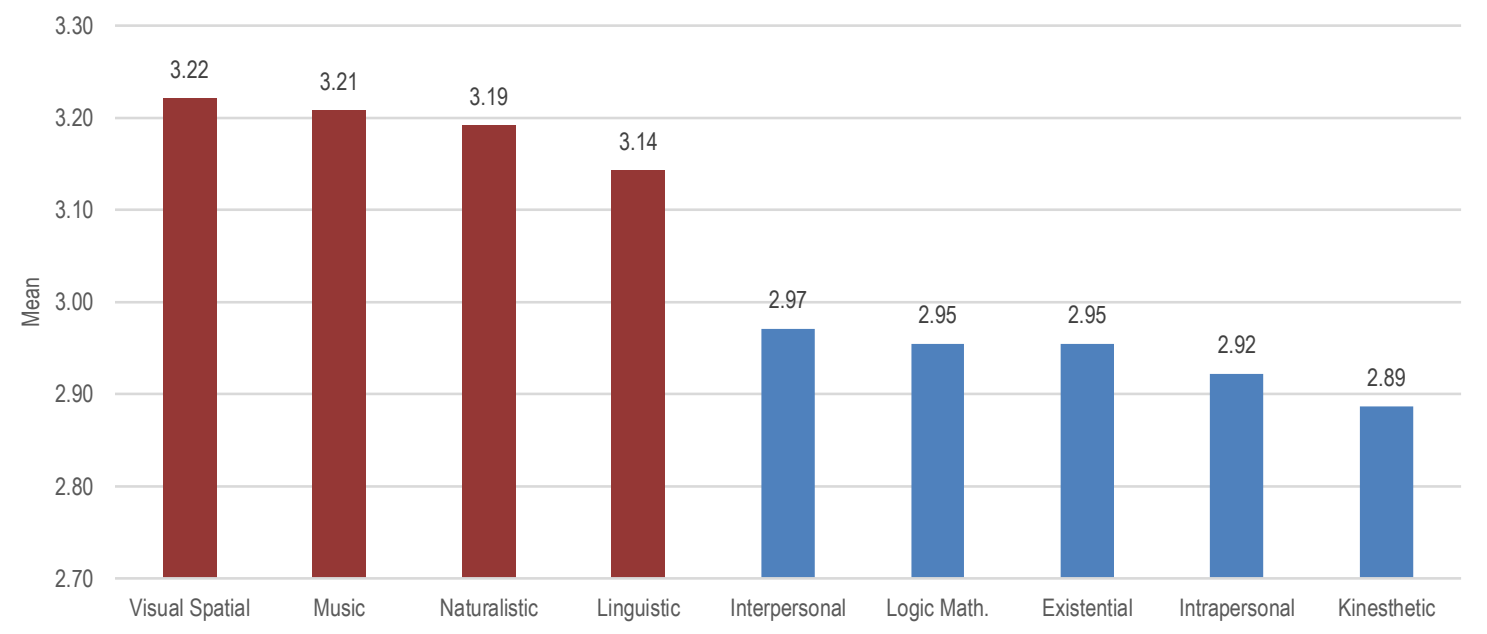

Figure 2. Respondents' multiple intelligence

Ideally, education should be matched to individual abilities and interests so that he/she can be appropriately challenged and maximally motivated to learn. According to Šafranj and Zivlak (2018), in multiple intelligence theory, intelligence can be associated with an individual's aptitude or potentials - the fact that an individual score either high or low in one specific area does not make him any more or less intelligent in the traditional sense. They also mentioned that visual-spatial intelligence could visualise space and objects within the mind's eye. People who prefer to use this kind of intelligence would instead draw a picture than write a paragraph. They notice colour, shapes and patterns and how light falls on the object, and comprehend mental model.e

According to González Campos, Sánchez-Navarro, and Arnedo-Moreno (2019), the statistical analyses developed in their study support the claim that studying computer graphic owns a positive influence on students which dominant in visual-spatial intelligence. Tasks requiring visual-spatial intelligence include packing (as when an individual must decide if a particular box is large enough for the objects you want to put into it) and using mirror images (as when an individual is combing his / her hair while looking into a mirror). Spatial ability is also imperative for progress in many fields of study. Mathematics, natural sciences, engineering, economic forecasting, meteorology and architecture all involve spatial skills. González Campos, Sánchez-Navarro, and Arnedo-Moreno (2019) also recommended that an individual's career options with the most robust visual-spatial intelligence are architecture, landscape architecture, and designer.

Thus, specifically, people with highly developed visual-spatial intelligence (Ibmian\&Hadban, 2013) are known to be competent at interpreting visual images, have a good sense of sketching and painting, and enjoy watching videos and movies. According to Babu and Ganesan (2019), the most acute senses necessary to compensate for the absence of vision in spatial tasks and empirical findings showed tactile training could enhance spatial knowledge acquisition. They discovered that spatial abilities showed that blind people's performance is superior to the one observed in low-vision and sighted people, suggesting that touch compensates for the absence of sight by allowing for the coding of spatial patterns to emanate from tactile instead of visual input. This observation is in line with studies that show brain activations in visual-spatial pathways both blind and sighted persons when acquiring tactile maps, indicating that cortical recruitment linked to spatial content only minimally depends on the visual system.

\subsection{Appropriate advanced courses for MBK}


The respondents' preferred courses are more to skills / vocational courses such as culinary, bakery, sewing, carpentry, entrepreneurs, logistics, and mechanics. This study's findings also uncovered that cooking and mechanic were two common professions that were an option regardless of whether MBK suffers from intellectual disability, dyslexia, or vision impairment (Table 5). Most of the choice of courses declared by MBK during the interview session was appropriate and realistic with the respondents who aspired to be chef, baker, tailor, carpenter, entrepreneur, and mechanic. Most of these courses are offered by GIATMARA (GIATMARA, 2021) and Jabatan Pembangunan Kemahiran (Jabatan Pembangunan Kemahiran, 2021) as well as other institutions including private colleges.

However, some respondents aspired to be a medical doctor, army, police, and firefighter. Although it was not impossible in such a situation, the respondent should be sensitive to academic achievement to achieve the ambitions that require top-notch academic results such as to become a medical doctor. Some respondents had vision impairment wanted to become policemen while the career requires a right level of vision. According to MohdRazimiHusin, Hishamuddin Ahmad, Ismail Yusuf Panessai, Norliza Abdul Majid, and AgusLokmanSulam (2020), mean in career goals learning method is higher than the learning with another method. That means the teacher can relate a career aspiration while teaching the disability students to give them a picture of course or field of study and its suitable career. Accordingly, it is also the accountability of teachers in schools to explain the proper employment field for each MBK at the school level to develop future careers.

Table 5. Respondents'Most preferedcourse

\begin{tabular}{lll}
\hline Disability & Prefered Course & \\
\hline Intellectual Disability & $\begin{array}{l}\text { Entrepreneurs, Cooking, Logistics, Mechanics, Carpentry, Sewing, } \\
\text { Bakery }\end{array}$ \\
\hline Dyslexia & Bakery, Cooking, Mechanics, Police \\
\hline Vision impairment & Mechanics, Cooking \\
\hline
\end{tabular}

Although there are assumptions in international studies that find that the best areas for MBK that have visualspatial strength are filmmaking, landscape architect, graphic designer, photographer, artist, and video animation, the field's choice may vary according to the situation, culture, different environments and countries. Many field options are suitable for MBK in other studies. However, this research found that the appropriate advanced or vocational course areas based on the response and requirements from MBK itself are the fields of cooking, bakery, sewing, carpentry, entrepreneurs, logistics, and mechanics. Based on MBK's wishes and interest in these areas of the course, the available career opportunities would allow MBK to work or be independent to support their future lives.

As shown in Figure 3, the framework can explain the advanced/vocational courses that are optional and found following the ability based on the dominant aspect in multiple intelligence that is visual-spatial intelligence. The framework also shows the career fields that can be pursued when they graduate later.

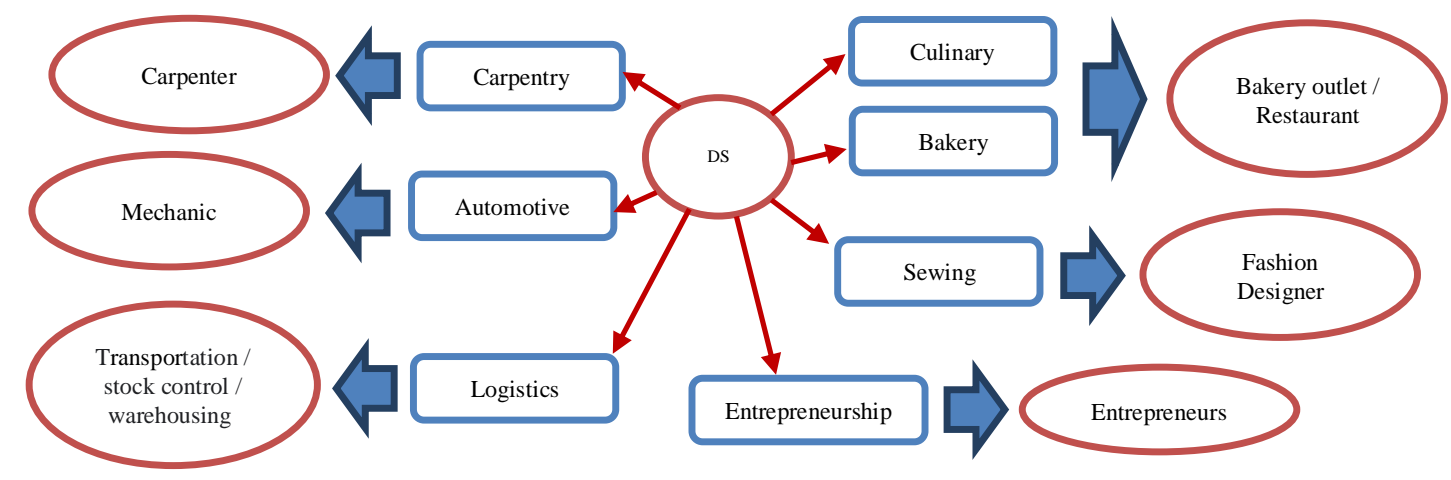

Figure 3. Respondents'framework for prefered course and future career

Visual-spatial intelligence is the ability to visualise space and objects within themind's eye. People who prefer to use this kind of intelligence would rather draw a picture than write a paragraph. They notice colour, shapes and patterns and how light falls on the object, and comprehend mental models. Visual-spatial intelligence is the ability to visualise space and objects within the mind's eye. People who prefer to use this kind of intelligence would rather draw a picture than write a paragraph. They notice colour, shapes and patterns and how light falls on the object, and comprehend mental models. Visual-spatial intelligence is the ability to visualise space and objects within the mind's eye. People who prefer to use this kind of intelligence would rather draw a picture than write a paragraph. They notice colour, shapes and patterns 
and how light falls on the object, and comprehend mental model. Intelligences can beassociated withan individual's aptitude or potentials - the fact that an individual score either high or low in one specific area does not make him any more or less intelligent in the traditional sense.

\section{CONCLUSION}

Ergo, we learn that MBK always expects external motivation to achieve success in the academic field. The tendency of MBK was also identified based on the multiple dominant intelligence, namely visual-spatial intelligence. This study too found that the dominant aspect of visual-spatial intelligence was closely related to appropriate course choice based on MBK's opinion. MBK's tendency to choosing courses that suit their interests could be identified based on multiple dominant intelligence. Furthermore, MBK's self-potential could be developed according to the areas in which they prefer more. The optional courses mentioned were very much in line with the dominant visual-spatial intelligence aspect.

Next, this study suggested a framework based on respondents' perceptions of their competence in academic success and multiple intelligence on advanced/vocational courses of their choice. Apart from providing opportunities for MBK to further their studies or skills in the field of interest, it also opened opportunities for MBK to be independent or build their career by using the knowledge and skills they have learned later. Therefore, this paper introduced a competency level for disability students framework to expose the students to their prefered courses and career pathway.

Preparing students for the workforce is one of the central roles for institution and stakeholders. Therefore, the stakeholders might consider the students' courses of choice to be offered more soon. With the right knowledge and thoughtful planning, students, students' parents, and the school could ensure that students obtain an outstanding education. Simultaneously, although the MOE provided one Transition Program to Careers for Students with Special Needs (MBK), it is hoped that the findings of this research could provide information on courses that become a real choice among MBKs for the consideration of the MOE and stakeholders.

Furthermore, the prospect of developing research results and application prospects of further studies into the next level might include all disabled students all over the country. That would render more cognisance into the courses following secondary school.

\section{ACKNOWLEDGEMENTS}

The authors wish to express our sincere appreciation to Universiti Pendidikan Sultan Idris for the research grant funding (Research Code: 2019-0210-107-01). Also greatly appreciations to the teachers and students studying at related schools who assisted in data collection.

\section{REFERENCES}

1. Babu, U. M., \& Ganesan, K. (2019). Visual-Spatial Skills for Visually Impaired Students. Conference: Universal Design for Learning Embedded With Assistive Technology for Children With Special Needs (UDLAT-2019) (pp. 1-6). Karaikudi : Alagappa University .

2. Cohen, R. J., \& Swerdlik, M. E. (2002). Psychological Testing and Assessment: An Introduction to Test and Measurement (5th ed.). McGraw-Hill Companies, Inc.

3. Daniel, J., \& Cooc, N. (2018). Teachers' Perceptions of Academic Intrinsic Motivation for Students With Disabilities. The Journal of Special Education, 1-12. doi:10.1177/0022466918765276

4. Gardner, H. (1983). Frames of Mind: Theory of Multiple Intelligences. New York: Basic Books Inc.

5. Gardner, H. (2011). Frames of Mind: The Theory of Multiple Intelligences. New York: Basic Books.

6. GIATMARA. (11 1, 2021). GIATMARA Malaysia. Retrieved from GIATMARA Malaysia, Kementerian Pembangunan Luar Bandar: http://giatmara.edu.my/language/ms/senaraikursus/?lang=ms\#toggle-id-7

7. González Campos, J. S., Sánchez-Navarro, J., \& Arnedo-Moreno, J. (2019). An Empirical Study of the Effect that a Computer Graphics Course has on Visual-Spatial Abilities. International Journal of Educational Technology in Higher Education, 16(41), 1-21. doi:https://doi.org/10.1186/s41239-0190169-7

8. Ibmian, K. S., \& Hadban, A. D. (2013). Implications of multiple intelligences theory in ELT field. International Journal of Humanities and Social Science, 3(4), 292-297.

9. Jabatan Pembangunan Kemahiran. (11 1, 2021). Portal Rasmi Jabatan Pembangunan Kemahiran. Retrieved from Jabatan Pembangunan Kemahiran, Kementerian Sumber Manusia: https://www.dsd.gov.my/index.php/perkhidmatan/sijil-kemahiran-malaysia-skm

10. Kail, R. V. (2001). Children and Their Development (2nd. ed.). New Jersey: Prantice-Hall.

11. Lay Yoon Fah, \& Khoo Chwee Hoon. (2014). Pengenalan Kepada Pendekatan Kuantitatif Dalam Penyelidikan Pendidikan. Kota Kinabalu: Universiti Malaysia Sabah.

12. Ministry of Education Malaysia. (31 12, 2020a). Retrieved from Garis Panduan Program Transisi ke Kerjaya Murid Berkeperluan Khas (MBK): https://www.moe.gov.my/pekeliling/3249-garis-panduanprogram-transisi-ke-kerjaya-murid-berkeperluan-khas-mbk/file 
13. Ministry of Education Malaysia. (2020b). Buku Data Pendidikan Khas 30 Jun 2020. Putrajaya: Kementerian Pendidikan Malaysia.

14. Ministry of Education Malaysia. (8 January, 2020c). Program Pendidikan Khas Integrasi. Retrieved from Program Pendidikan Khas Integrasi: https://www.moe.gov.my/pendidikan/khas/programpendidikan-khas-integrasi

15. MOE Examination Board. (2014). Manual Pentadbiran Pentaksiran Psikometrik Tingkatan 3. Putrajaya: Kementerian Pendidikan Malaysia.

16. Mohd Razimi Husin, Hishamuddin Ahmad, Ismail Yusuf Panessai, Norliza Abdul Majid, \& Agus Lokman Sulam. (2020). Inductive instructional approach, career aspiration and noble values in history. International Journal of Evaluation and Research in Education, 9(1), 162-167.

17. Perak State Education Department. (2018). Jabatan Pendidikan Negeri Perak. Retrieved from jpnperak.moe.gov.my

18. Prevatt, F., Huijun, L., Welles, T., Festa-Dreher, D., Yelland, S., \& Lee, J. (2011). The academic success inventory for college students: Scale development and practical implications for use with students. Journal of College Admission, 26-31.

19. Šafranj, J., \& Zivlak, J. (2018). Spatial-Visual Intelligence in Teaching Students of Engineering. Research in Pedagogy, 8(1), 71-83.

20. Special Education Division. (2014). Kod Amalan Pendidikan Murid Berkeperluan Khas. Putrajaya: Kementerian Pendidikan Malaysia.

21. Thomas, A., \& Grimes, J. (2002). Best practices in school psychology IV. National Association of School Psychologists, 1569-1584.

22. University of Massachusetts. (13 1, 2021). Promoting Positive Social Interactions in an Inclusion Setting for Students with Learning Disabilities. Retrieved from National Association of Special Education Teachers: http://faculty.uml.edu/darcus/01.505/naset_social_inclusion.pdf

23. Vasuden, A. (2017). Slow learners - Causes, problems and educational programmes. International Journal of Applied Research, 3(12), 308-301. 